\title{
Management of the Engineers Mathematical Education Processes via Nomotex DLS
}

\author{
Yury I. Dimitrienko ${ }^{1}$, Elena A. Gubareva ${ }^{1 *}$, Dmitry A. Chebakov ${ }^{1}$, and Ivan A. Tumanov ${ }^{1}$ \\ ${ }^{1}$ Bauman Moscow State Technical University, 2nd Baumanskaya str., 5/1, 105005, Moscow, Russia
}

\begin{abstract}
The paper presents innovative approaches using the Big Data concept to the management of the educational process, implemented in digital media content - the Nomotex information and educational environment (Nomotex DLS), created at the Department of Computational Mathematics and Mathematical Physics of the Bauman Moscow State Technical University.
\end{abstract}

\section{Introduction}

When analyzing the development paths of university education, special attention is paid to the use of new information and digital technologies, such as virtual reality, the creation of MOOCs, 3D visualization, etc. At the same time, the process of managing the educational process, which is inextricably linked with the organization of educational work, the organization of methodological work, information technology in the educational process and control is transformed into a management process based on the methods and technology of Big Data [1-7].

One of the most common problems in the organization of the educational process is the theoretical level of classes conducted by teachers, the correspondence of the material prepared by the teachers to the work program of the discipline, the presentation of the cross-cutting mathematical concepts of various disciplines by the teachers. When creating the Nomotex DLS, all of the above issues were taken into account.

\section{Structure of educational process control systems via Nomotex DLS}

In the Nomotex DLS, subsystems have been created for the implementation of neural network educational programs, in which the material of a discipline corresponding to a certain direction of training (specialty) is fully presented. The hierarchical structure of the Nomotex DLS [8-11] eliminates the problem of presenting cross-cutting mathematical concepts.

The following specialized tools have been developed to manage the educational process at the Nomotex DLS:

- subsystem «Implementation of neural network programs»;

*Corresponding author: gubareva_ea@bmstu.ru 
- subsystem «Administration»;

- subsystem «Teacher's Personal Account»

- subsystem «Student's Personal Account», with a student's progress rating, flexibly changing for each course;

- subsystem «Automated ticket distribution» for all Control events (midterm control, control work, homework, lecture microcontrol, interim certification (exam));

- subsystem «Performance Analysis»;

- subsystem «Self-learning by intelligent intelligence (II)» based on Big Data for student self-training;

- subsystem «Digital Trace».

Figures 1 and 2 show the windows of the «Teacher's Personal Account» subsystem (Fig. 1) and the «Administration» subsystem (Fig. 2).

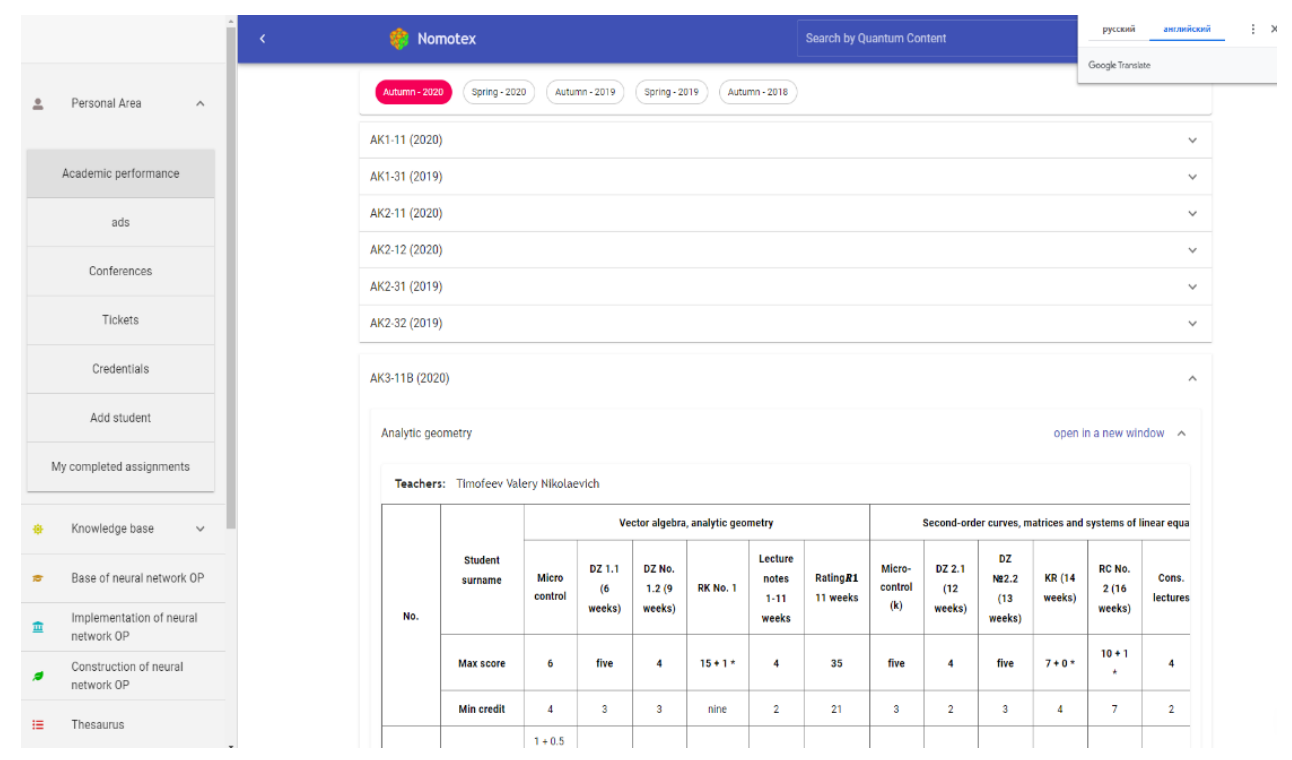

Fig. 1. The window of the «Teacher's Personal Account» subsystem in the Nomotex DLS.

D,ango administration

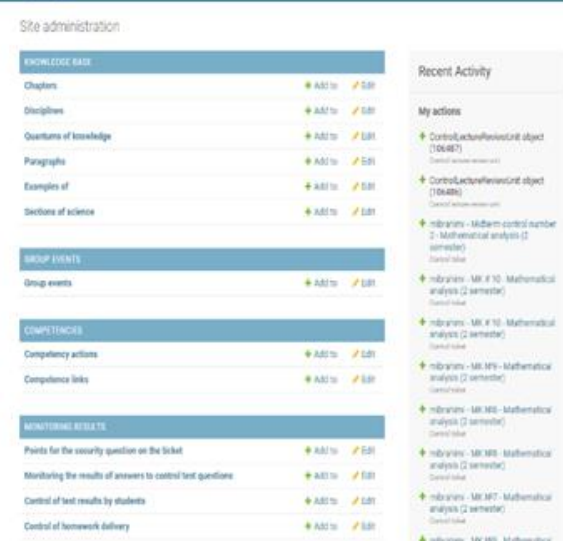

Fig. 2. The window of the «Administration» subsystem in the Nomotex DLS. 


\subsection{Subsystem «Implementation of neural network programs»}

The subsystem «Implementation of neural network programs» fully meets the needs associated with the organization of educational work, the organization of methodological work and the use of information technology in the educational process. In this subsystem, we can select an Educational program and see all the courses that are taught in this educational program.

After choosing a course, you can see the entire structure of the course, and you can also select only the components of the structure of the course: lectures, seminars or lectures and seminars.

The teacher, reading the training course, works precisely in this subsystem. For the convenience of work in the subsystem «Implementation of neural network programs» a tool has been created that allows the teacher to mark the passed quanta. This functionality is very convenient, because, in practice, the teacher very often either does not have time to read the lecture to the end, or, on the contrary, begins to read the next lecture.

\subsection{Subsystem «Teacher's personal account»}

In the subsystem «Teacher's Personal Account», the teacher can issue tickets for control events and add information about control events, and can control the methodological content of courses and statistics on students' homework, independent work, midterm control.

For contact work with students on the Nomotex DLS, two functions «Announcements» and «Video-Conference» have been created.

The functionality «Announcements» is a platform for the exchange of information messages, which provides two-way communication between the teacher and students (Fig. 3). The teacher can post messages to a stream consisting of several groups, a separate group, an individual student. For the convenience of the teacher and student, a search with a filter has been added to this functionality, which sorts messages by semester, groups, disciplines, and specific students.

In addition to informational messages, it is possible to attach different types of files for the exchange of content between a teacher and a student. The priority of the teacher's messages is higher than that of the student, since the teacher can edit his messages, but the student does not have this option.

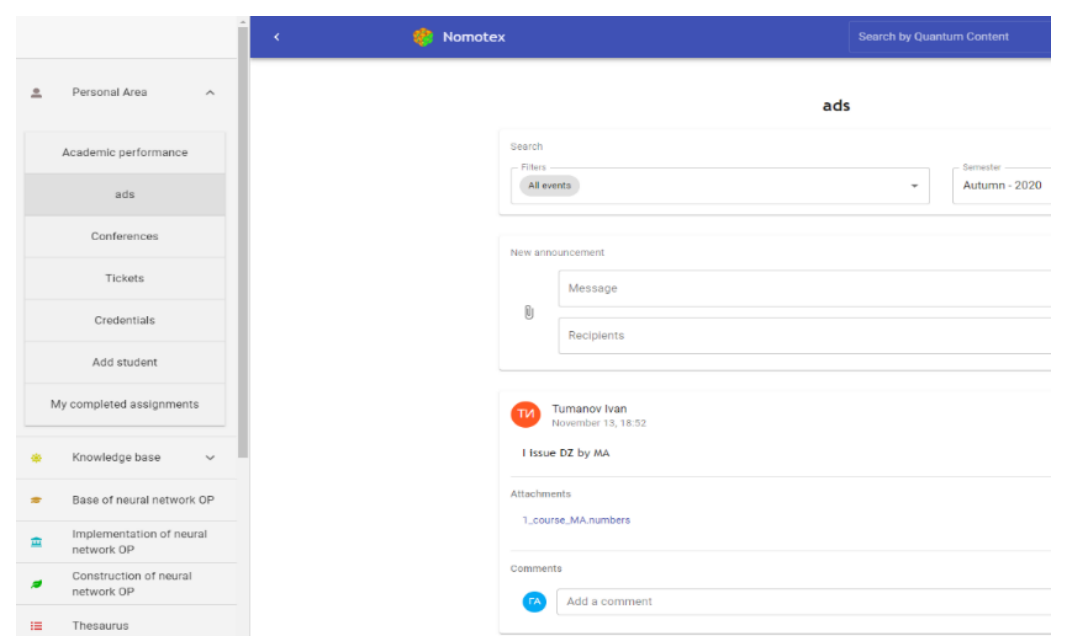

Fig. 3. Window of functional «Announcements» in the Nomotex DLS. 
The «Video Conference» functionality is intended for conducting online seminars and lectures on the Nomotex DLS. The teacher creates a conference: gives the name of the conference and selects from the list of conference participants: groups, individual students. After creating a conference, a link to this conference appears in the teacher's personal account and conference participants' personal accounts and offers to connect to it (Fig. 4).

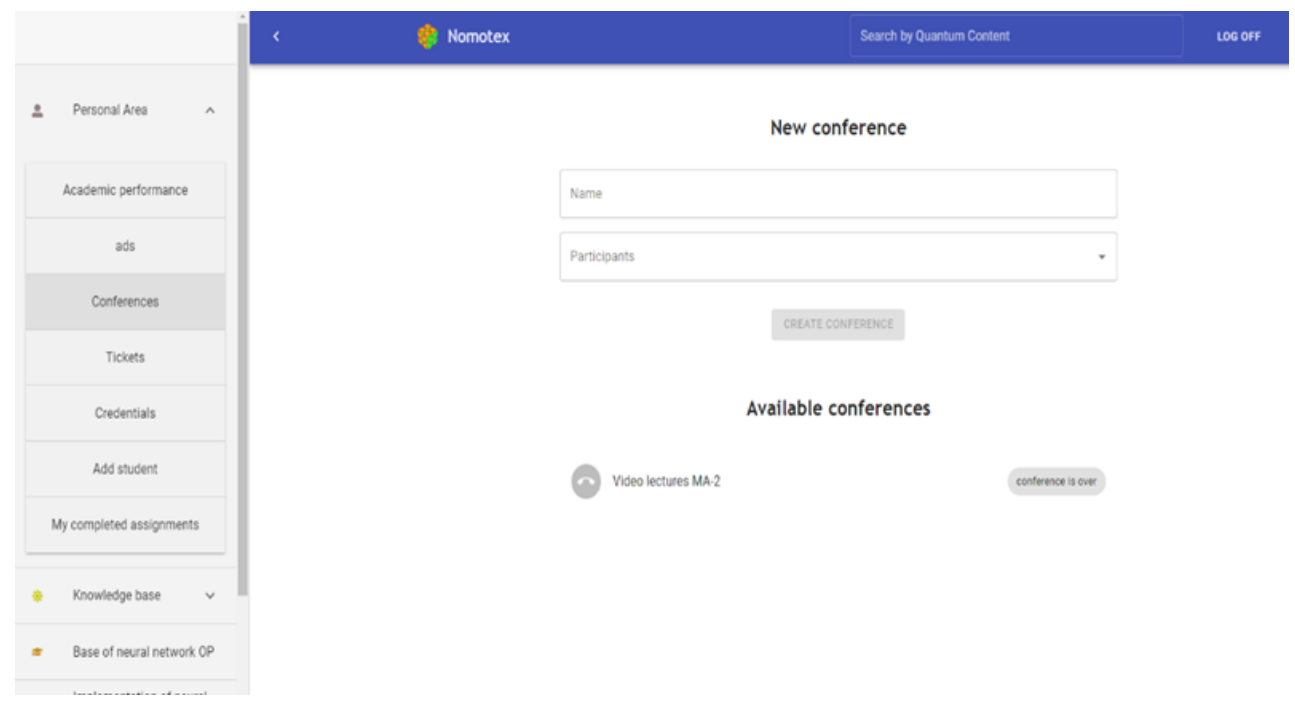

Fig. 4. Window of functional «Video-Conference» in the Nomotex DLS.

The conference is held on the Big Blue Button video platform, which is equipped with the following functionality: chat, conference recording, the ability to take notes, as well as launch various multimedia materials, and of course, demonstrate educational content of the Nomotex DLS in a specific discipline.

\subsection{Subsystem «Student's personal account»}

In the subsystem «Student's personal account» the student performs homework, independent work, midterm controls.

In addition, all the results of mastering the discipline are stored in the student's office the «Digital Educational Trace», which over time is transformed into an individual educational trajectory of this student.

The teacher can see all the data of the student (Fig. 5). Depending on the intermediate results of academic performance for each control event (lecture microcontrol, homework, control work, midterm control and exam), the teacher leading the group lessons, if necessary, organizes additional control events, which also take place in an automated mode, with the issuance of additional tickets. Arising controversial situations that are possible with an automated method of assessing knowledge (errors in entering an answer, technical problems of the stability of the system, ambiguous answers, etc.) are resolved by the teacher individually, in the presence of written records that the student make in the process of automated knowledge assessment.

The student's performance rating for each mathematical discipline consists of modules (individual completed topics of the discipline) (Fig. 6). 


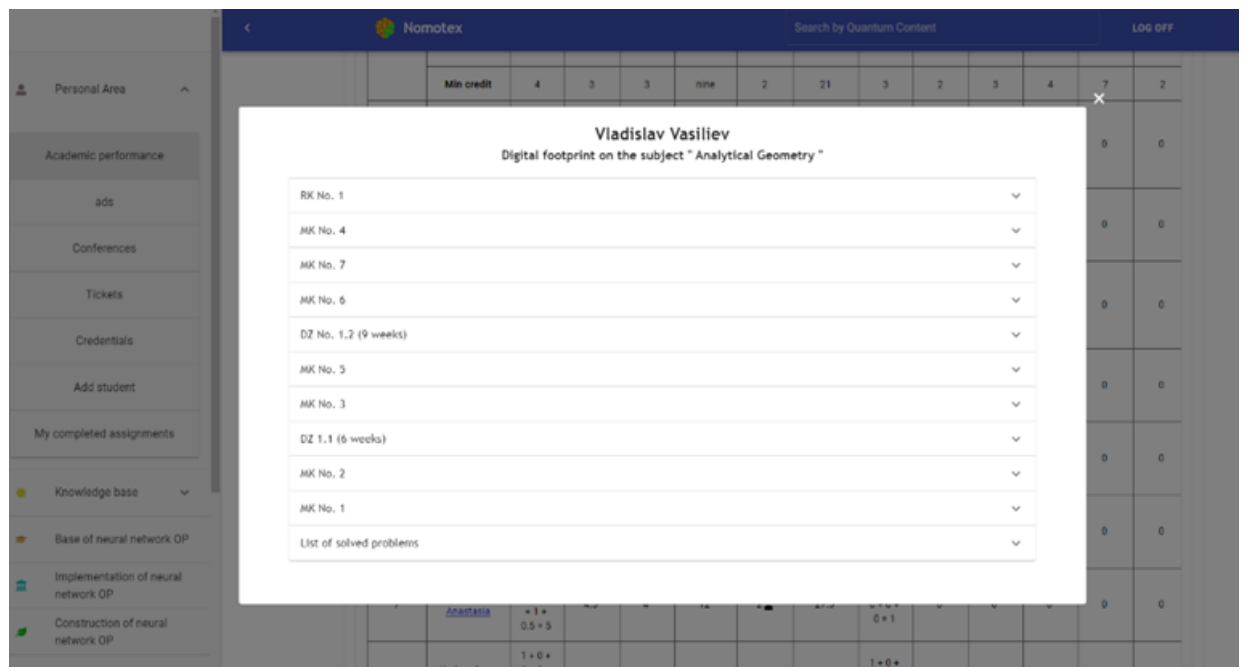

Fig. 5. The data window of control events, which was passed by the student at the Nomotex DLS.

Each module is a set of control activities, evaluated in points.

The control event (CE) is considered passed by the student if the student scored the minimum number of points for the given CE.

For the contact work of a student with a teacher in the subsystem «Student's Personal Account», the "Announcements» functionality has been created (Fig. 3), which provides two-way communication. Using this functionality, a student can write informational messages with attached files to his teacher, as well as receive information from the teacher and comment on it.

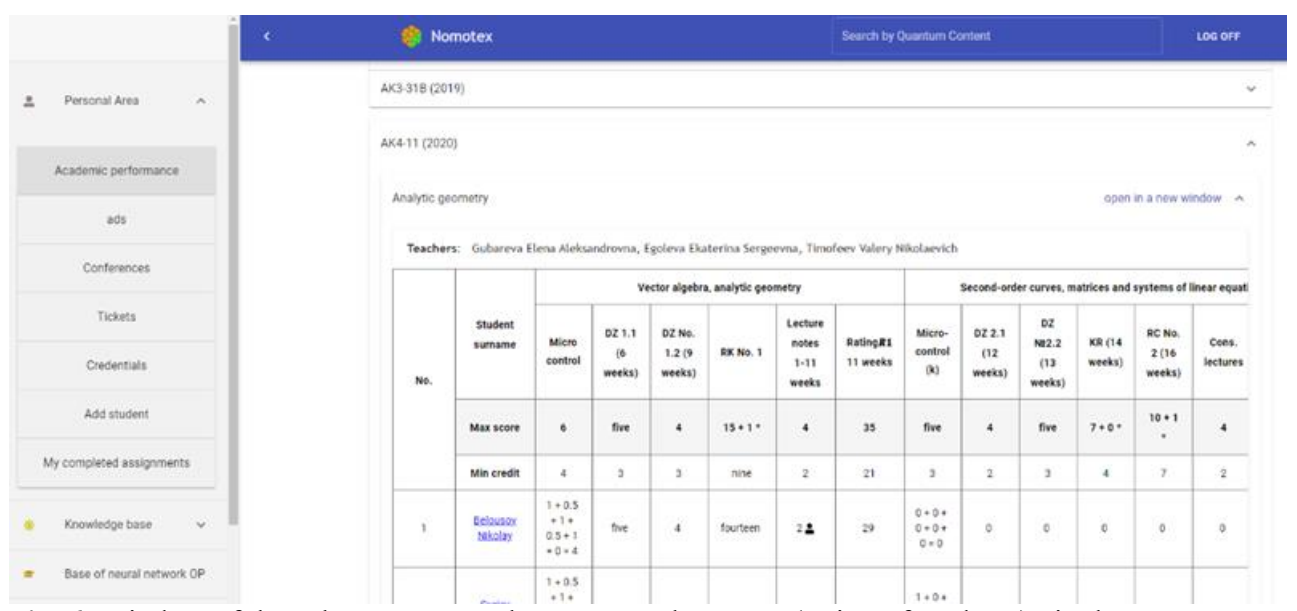

Fig. 6. Window of the subsystem «Teacher's personal account (rating of students)» in the Nomotex DLS.

\subsection{Subsystem «Automated ticket distribution»}

The procedure for the automated issuance of tickets for CE is as follows. The Nomotex system implements three types of automatic issuance:

1) Tickets are issued automatically without proctoring. 
This type of issue can be used in the classroom, where all CE students write under the supervision of a teacher. The system issues tickets randomly. No two students in a group come across the same tickets.

2) Tickets are issued in an automated mode with asynchronous proctoring. This type of issue can be used remotely when the teacher cannot observe the students. And after the students pass the $\mathrm{CE}$, the teacher looks at the videos on the proctor-service portal to observe the rules for writing the CE.

3) Tickets are issued in an automated manner with synchronous proctoring.

This type of issue is carried out remotely, when a teacher in real time observes students remotely using a proctor service.

One of the «innovative» types of control measures in the Nomotex DLS is «lecture microcontrol». This CE is designed to improve the quality of the study of lectures. CE are built on lecture materials and test the theoretical knowledge of students. CE «lecture microcontrol» are given by the lecturer in an automated mode at the beginning of lectures. For students, this CE is an incentive to study theoretical material. The name of this CE is associated with the time interval of -15 minutes.

\subsection{Subsystem «Performance Analysis»}

The performance analysis subsystem is formed on the basis of student rating data and is presented in Fig. 7, which provides complete statistics for the group.

Here we see the percentage of students who passed each test, as well as the percentage of students who completely closed the training module.

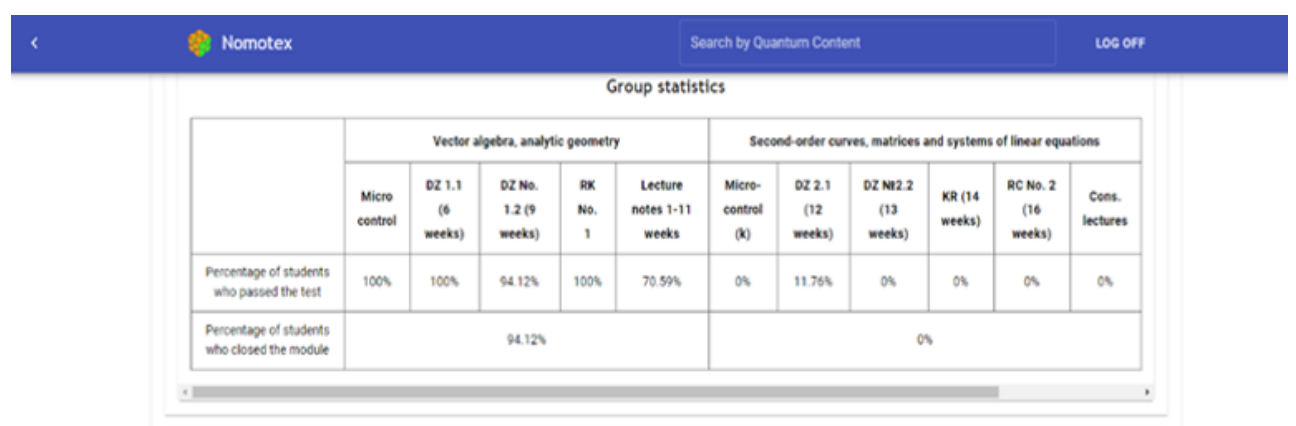

Fig. 7. Window of the subsystem «Performance Analysis» in the Nomotex DLS.

\subsection{Subsystem «Self-learning by intelligent intelligence (II)»}

A subsystem with II based on Big Data is intended for student self-training. This system is designed to automatically adapt to each student. On the basis of data analysis - the number of solved problems, their type, the system offers to solve exactly those problems in which the student has difficulties, raising the level of the next problem with the successful solution of the previous problem.

The Big Data concept of the Nomotex DLS makes it possible to evaluate and compare the educational trajectories of students, students themselves, teachers of the same math courses, as well as educational programs themselves in real time. 


\subsection{Subsystem «Digital Trace»}

To build an individual educational trajectory of a student in the Nomotex DLS, a subsystem "Digital trace" (Fig. 8) was created, which step by step reflects the learning process of a particular student, thus forming an individual trajectory of the learning process of this student. In addition, the base of the student's achievements is formed at a specific stage of studying the subject and completing assignments: independent work, homework, midterm control.

By analyzing the "Digital Trace", the teacher can see problematic topics of study for a particular student, as well as check the dates of each assignment, the number of attempts, and the final result. Everything that a student performs in the system is systematized according to specific types of tasks: lecture microcontrol, midterm control, independent work, homework. If the task is completed correctly, then it is reflected in the green field, if partially completed - in the yellow field, if the task was completed incorrectly - in the red field, and for each task the student receives a certain number of points, according to the module-rating system for a specific discipline.

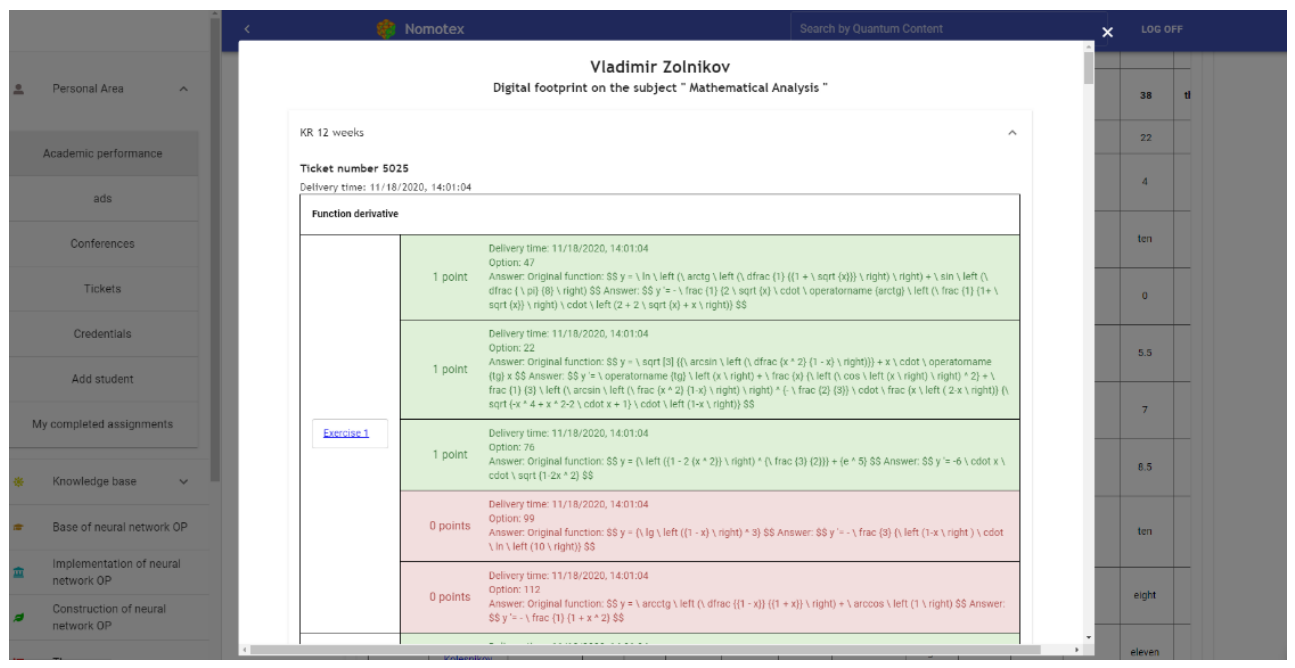

Fig. 8. Window of the subsystem «Digital Trace» in the Nomotex DLS.

\section{Conclusions}

The Nomotex DLS implements new approaches to the management of the educational process, based on the transformation of the organization of educational work, the organization of methodological work and control. Most of the controls occur automatically, as a result of this process Big Data is formed. And already Big data analysis allows you to flexibly make the necessary decisions to improve process management. These and some other elements of the methodology make it possible to quickly and effectively manage the teaching of mathematical disciplines in the Nomotex DLS in dynamics, starting from a separate «mathematical problem» to the entire «educational program». 


\section{References}

1. S.D. Reznik, Upravleniye kafedroy. Izdaniye tret'ye, pererabotannoye i dopolnennoye, Moskva, INFRA-M, 607 s.(2011)

2. I.G. Zakharova, Big data i upravleniye obrazovatel'nym protsessom, Gumanitarnyye issledovaniya, Humanitates, Tom 3 № 1, (2017)

3. N.A. Serdyukova, V.I. Serdyukov, Smart System Sustainability and Smart System Management (to be published) Intelligent Systems Reference Library, 191, pp. 157172, DOI: 10.1007/978-3-030-54470-6_9 (2021)

4. E.V. Lyapuntsova, I.M. Belozerova, V.G. Borkovskaya, I.I. Drozdova, Y.S. Baranova, Organization and Management of Educational Work in Universities in the Light of National Strategic Guidelines for the Development of Education, IOP Conference Series: Earth and Environmental Science, 459 (6), № 062031, DOI: 10.1088/1755-1315/459/6/062031 (2020)

5. A. Yermakov, I. Stroganov, A system for modelling and visualizing processor state during code execution, eLearning and Software for Education Conference, pp. 438443. DOI: 10.12753/2066-026X-19-058 (2019)

6. V.A. Shakhnov, A.A. Glushko, E.V. Rezchikova, L.A. Zinchenko, V.V. Terekhov, V.V. Makarchuk, TCAD and Cognitive Visualization in Electronic Engineering Education : BMSTU Case Study, 2020 5th International Conference on Information Technologies in Engineering Education, Inforino 2020 - Proceedings, № 9111802, DOI: 10.1109/Inforino48376.2020.9111802 (2020)

7. T.Yu. Tsibizova, V.M. Postnikov, S.B. Spiridonov, Analysis of the impact of technology lectures-visualizations on the results of control measures in various academic disciplines, Perspektivy Nauki i Obrazovania, 33 (3), pp. 358-363(2018)

8. Yu.I. Dimitrienko, E.A. Gubareva, A new technology for the mathematical training of engineering personnel based on a neural network model of knowledge, Innovations in Education, No. 11, pp.129-140 (2017)

9. Yu.I. Dimitrienko, E.A. Gubareva, Hierarchical neural network model for mathematical knowledge and software NOMOTEX for mathematical training of engineers, IOP Journal of Physics: Conference Series, volume 1141 012010, DOI:10.1088/1742-6596/1141/1/012010 (2018)

10. Yu.I. Dimitrienko, E.A. Gubareva, T.V. Oblakova, A.A.Prozorovskiy, Primeneniye tsifrovoy obrazovatel'noy credy NOMOTEX dlya obucheniya inzhenerov po kursu «Analiticheskaya geometriya», Dnevnik nauki, № 10 (22), pp. 7-15 (2018)

11. Yu.I. Dimitrienko, E.A. Gubareva, D.A Chebakov, Konstruirovaniye elektronnykh interaktivnykh kursov v tsifrovoy obrazovatel'noy srede NOMOTEX, Dnevnik nauki, №11, http://dnevniknauki.ru/im...ubareva_Chebakov.pdf (2019) 